\title{
PERCEIVED HYPERNASALITY IN THE PRESENCE OF ADEQUATE VELOPHARYNGEAL CLOSURE AS MEASURED BY AERODYNAMIC STUDIES
}

\author{
By \\ Mona Hegazi*, Nirvana Gamal el Din*, Tamer Abou-Elsaad**, \\ Rasha Shoeib* and Sabah Hassan*
}

\author{
From \\ - Unit of Phoniatrics, ORL Department, Ain Shams Faculty of Medicine \\ "* Unit of Phoniatrics, ORL Department, Mansoura Faculty of Medicine
}

\begin{abstract}
It was found that there was a group of patients with repaired cleft palate who demonstrated a discrepancy between aerodynamic assessment of velopharyngeal (VP) adequacy and clinical judgement of nasal resonance. The aim of this work is to study such group of patients in order to understand and explain this discrepancy. This study comprised 37 subjects divided into two groups. The first group comprised 12 patients with the diagnosis of repaired overt or submucus cleft palate with an age range of 5 to 25 years (mean age $=13$ years). This group showed an audible degree of hypernasality in their speech while they have adequate VP port area by aerodynamic measures. The second group ( $n=25$ ) comprised age and sex matched normal subjects who
\end{abstract}

demonstrated normal resonance of speech. All the subjects were assessed subjectively for the degree of open nasality on a 4-point scale and objectively by acoustic and aerodynamic studies.

Acoustic studies demonstrated a highly significant difference in the nasalance scores between both groups. Aerodynamic studies demonstrated a statistically non-significant difference concerning nasal flow and intra-oral and nasal pressure findings between both groups. While, on the other hand, the timing of both the nasal flow and the intra-oral pressure showed highly significant difference between both groups. Also, the nasal flow peak show a highly significant shift to the right with delay in flow in relation to the intra-oral pressure.

MANSOURA MEDICAL JOURNAL 
tients with repaired cleft palate who demonstrated a discrepancy between aerodynamic assessment of velopharyngeal adequacy and clinical judgement of nasal resonance. The speech of those patients were Judged as hypernasal although VPA was less than $5 \mathrm{~mm}^{2}$ by aerodynamic measures. In 1993, Warren et al. ${ }^{4}$ tried to explain this phenomenon on the basis of a timing disorder of VP closure.

The aim of this work is to study such group of patients with repaired cleft palate who demonstrated an audible degree of hypernasality in their speech while they have adequate VPA by aerodynamic measures in order to understand and explain this discrepancy between the subjective perceptual ratings and the objective aerodynamic measures.

\section{MATERIAL AND METHODS}

This study comprised 37 subjects divided into two groups. The first group comprised 12 patients who attended the Phoniatrics Unit, Ain Shams University Hospitals with the diagnosis of repaired overt or submucus cleft palate. They were 6 males and 6 females with an age range of 5 to 25 years (mean age $=13$ years). This group showed an audible degree of hypernasality in their speech while they have adequate VPA by aerodynamic measures. The second group $(n=25)$ comprised age and sex matched normal subjects who demonstrated normal resonance of speech. None of the subjects of either group demonstrated hearing loss, mental subnormality or neuromuscular disorders.

All the subjects were assessed subjectively and objectively as follows :

(A) Subjective asessment:

Auditory perceptual assessment of the degree of open nasality of all subjects was judged by 3 clinicians on a 4-point scale:

$0=$ normal (no audible open nasality ).

1 - mild degree of open nasality .

2 = moderate degree of open nasality .

$3=$ severe degree of open nasality

(B) Objective measures:

(1) Acoustic measures: The VPA of all subjects were assessed using Kay Elemetrics Nasometer (model $6200-2$, version 1.5) for measurement of nasalance scores for an oral sentence (/ali rah jel'ab korah/) on the basis of calculating the ratio of nasal to

MANSOURA MEDICAL JOURNAL 
B) PERCI readings :

i) Flow and pressure findings : All items entering the equation were compared between both groups to determine any differences in their results. It was found that all parameters showed statistically non-significant difference $(P>0.05)$ although VP port areas showed a tendency for higher mean results in the patients group than the normal group (table 2). ii) Timing results : The timing of both the nasal flow and the intra-oral pressure showed highly significant difference $(p<0.01$ ) between both groups with group 1 producing more durations than group 2. The nasal flow peak also showed a highly significant shift to the right with delay in flow in relation to the intra-oral pressure $(p<0.01)$ (table 3 ).

Table (1): Results of nasalance scores of group 1 (patients, $n=12$ ) and group 2 (normal subjects, $n=25$ ) as compared by T-test:

\begin{tabular}{|c|l|l|l|l|}
\hline Measures & Group 1 & Group 2 & $\begin{array}{l}\text { T- } \\
\text { value }\end{array}$ & $\begin{array}{l}\text { P-value and } \\
\text { significance }\end{array}$ \\
\hline Nasalance (\%) & $41.3 \pm 21$ & $15.1 \pm 5$ & 12.5 & $\mathrm{P}<0.01 \mathrm{HS}$ \\
\hline
\end{tabular}

HS = highly significant

Table (2): Results of flow and pressure findings of group 1 (patients, $n$ $=12$ ) and group 2 (normal subjects, $n=25$ ) as compared by T-test:

\begin{tabular}{|l|l|l|l|l|}
\hline \multicolumn{1}{|c|}{ Measures } & Group 1 & Group 2 & $\begin{array}{l}\text { T- } \\
\text { value }\end{array}$ & $\begin{array}{l}\text { P-value and } \\
\text { significance }\end{array}$ \\
\hline Nasal Flow (L/s) & $20.7 \pm 15$ & $16.1 \pm 13$ & 1.07 & $\mathrm{P}>0.05 \mathrm{NS}$ \\
Intra-oral pr. $\left(\mathrm{cm} \mathrm{H}_{2} \mathrm{O}\right)$ & $3.9 \pm 2$ & $6.4 \pm 4$ & 1.9 & $\mathrm{P}>0.05 \mathrm{NS}$ \\
Nasal pr. $\left(\mathrm{cm} \mathrm{H}_{2} \mathrm{O}\right)$ & $0.86 \pm 0.7$ & $0.45 \pm 0.3$ & 1.3 & $\mathrm{P}>0.05 \mathrm{NS}$ \\
Oral-nasal pr. & $3.0 \pm 2.4$ & $6.0 \pm 3.6$ & 2.1 & $\mathrm{P}>0.05 \mathrm{NS}$ \\
VPA (mm (mm $^{2}$ & $1.9 \pm 0.5$ & $1.1 \pm 0.7$ & 1.9 & $\mathrm{P}>0.05 \mathrm{NS}$ \\
\hline
\end{tabular}

$\mathrm{VPA}=$ velopharyngeal orifice area

NS $=$ non-significant 
flow must occur during the oral pressure-rise phase. There should be no nasal flow at the oral pressure peak. In the patients' group the shift of the flow curve to the right is indicative of nasal flow associated with the pressure peak. This explains why these patients have perceived open nasality.

The proionged open time for the VP orifice is confirmed by Dalston et al. ${ }^{7}$ and Warren et al. 4 who described similar findings in a group of patients who demonstrated hypernasality with normal VP port areas. Dalston et al. 7 explained the timing delay by adjustments that were presumed to be necessary in order to compensate for differences in VP movement capabilities. However, Warren et al. ${ }^{4}$ also found that patients had significantly lower nasal airflow rates than normal non-cleft subjects. Nevertheless, they suggested that the time where the nasal chamber is open to the vocal tract was more important to determine the degree of open nasality than the actual amount of airflow escaping through the nose.

The current study indicates that the acoustic measurements using nasometer may be more sensitive in detection of open nasality than aerodynamic measurements using PERCI. Moreover, the results of the latter should be carefully interpreted when a discrepancy occurs between perceptual judgments and VP port areas. It is recommended that the velopharyngeal closure patterns for other conditions associated with VPI such as hearing impairment, mental retardation and neuromuscular disorders be studied in order to evaluate their closure patterns. The present study also indicates that in rehabilitation of such patients it may not be enough to have the patient try to minimize hypernasality by reducing expiratory effort. The duration of closure should also be shortened perhaps through visual feedback using PERCI for better outcome.

\section{REFERENCES}

1. Mc Williams, B.J. ; Morris, H.L. and Shelton, R.L. (1984) : Cleft Palate Speech. publisher: B.C. Decker inc. pp. 168-205.

2. Kotby, M .N.; Abd Al Haleem, E.

K.; Hegazi, M.; Safe, I. And Zaki, M. (1997) : Aspects of assessment and manage-

MANSOURA MEDICAL JOURNAL 


\section{الخنف المفتوح المسموع فى وجود قياسات طبيعية للصمام اللهائى البلعومى باستخدام دراسة ديناميكية الهواء}

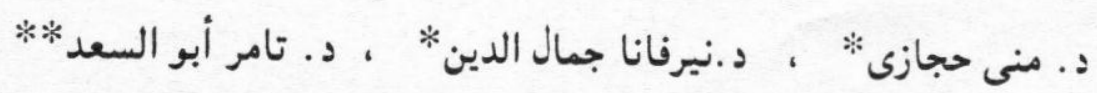

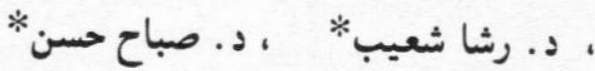

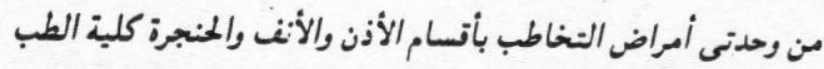

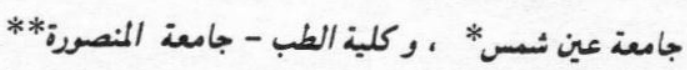

وجد أنه فى مجسوعة من مرضى شتق سقن الحلق والذى أجريت لهم جراحة لاصلاح الشتق، أنهم يعانوا

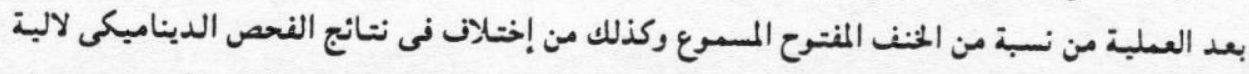

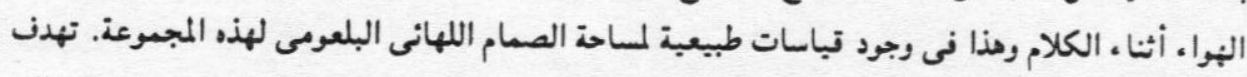

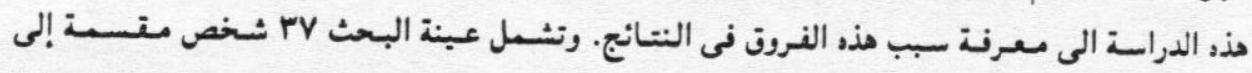

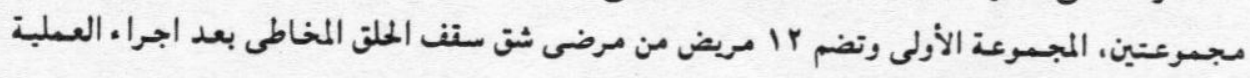

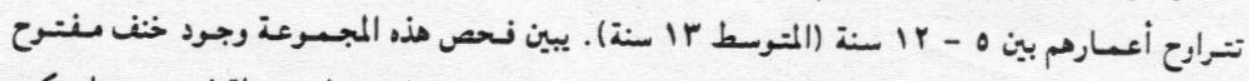

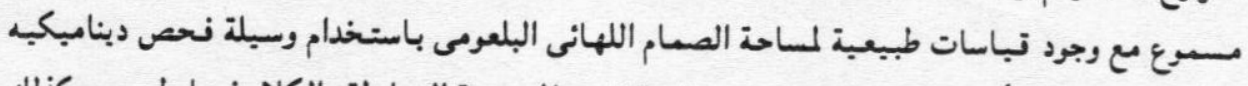

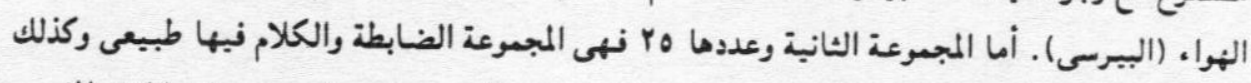

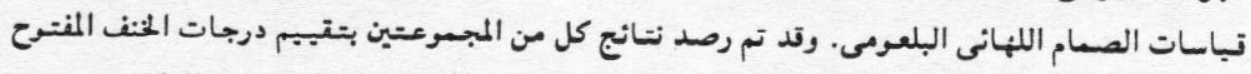

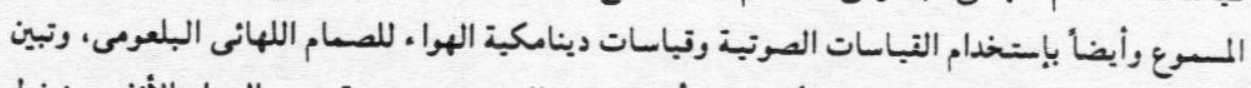

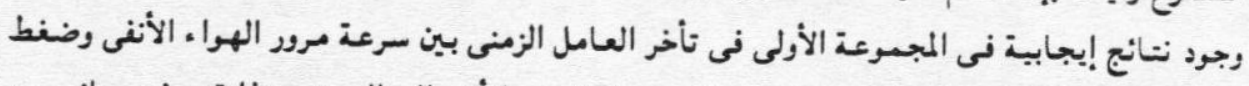

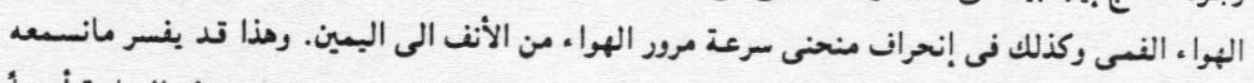

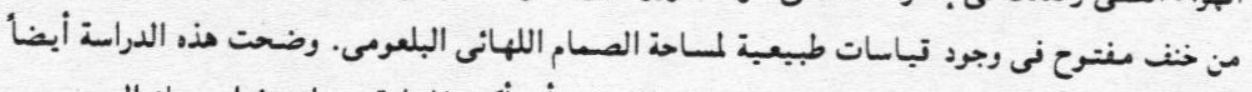
أهبة النازومبتر كوسبلة نعالة نى تباسات المنن المنتوح وأنه أكثر فاعلبة عن إستخدام جهاز البيرسى. 